Supplement of Biogeosciences, 15, 1549-1557, 2018

https://doi.org/10.5194/bg-15-1549-2018-supplement

(C) Author(s) 2018. This work is distributed under

the Creative Commons Attribution 4.0 License.

(c) (1)

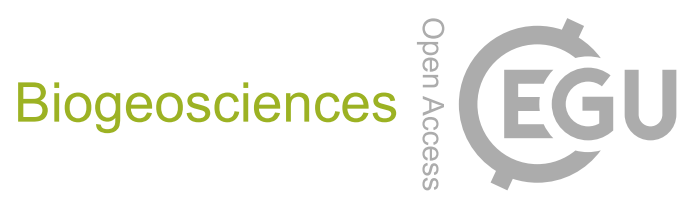

Supplement of

\title{
Technical note: A simple approach for efficient collection of field reference data for calibrating remote sensing mapping of northern wetlands
}

Magnus Gålfalk et al.

Correspondence to: Magnus Gålfalk (magnus.galfalk@liu.se)

The copyright of individual parts of the supplement might differ from the CC BY 4.0 License. 


\section{Supplementary material S1 - Manual}

Preparations - what is needed?

- A remote controlled camera with a wide field of view is required, e.g. a GoPro with a waterproof casing

- Remote control for the camera (e.g. an app on a mobile phone or tablet).

- A tripod and/or monopods giving an extendable total length of at least $3 \mathrm{~m}$ (e.g. a tripod and a monopod put together). $>4 \mathrm{~m}$ height is preferred.

- Note the camera model (if known also the horizontal and vertical field of view in degrees). This is important to be able to obtain the projected geometry.

- A GPS for recording GPS position of the plots

- A log to write camera altitudes, plot descriptions etc.

- Make a calibration photo of the ground, with several distances marked on the ground in both directions (see Fig. 5 which is our calibration image after correction for lens distortion). Note the camera altitude used. Other altitudes can be used in the field although only one calibration photo is needed.

For each field plot:

1. One person holds the extended tripod supported by the ground (Fig. 1) or lifts it up for higher camera altitudes (e.g. when tall vegetation such as bushes are present).

2. Imaging should be done from an altitude of at least $3 \mathrm{~m}$ (for a 90 degree field of a view and $10 \times 10 \mathrm{~m}$ area)

Alternative 1 (which we have used) is to stand at the edge of a plot and tilt the camera so that the horizon appears close to the top of the image (Fig. 2A). This horizon coordinate can then be used in post-processing to find angles in the image. With a vertical field of view of at least 90 degrees, nadir angles will also be present in the same image.

Alternative 2 is to stand in the center of the plot and tilt the camera straight down (nadir direction). This will make all the angles in the image closer to nadir which makes the classifications easier (as tall vegetation will not obscure the view towards lower vegetation as much). The person and tripod will be included in the image using this method but will only take up a small part of the image which can be avoided in post processing classification.

3. Another person notes the camera height, GPS position, the direction of the field of view relative to the GPS position, and uses a remote control (such as an app on a water proof mobile phone) to take an image of the plot. The time should be noted in the log for each plot so that images can be matched to the correct GPS positions. 
4. Take 3-4 close-up images (Fig. 7) of main classes of land cover (e.g. the most dominating plant types in the area). By tilting the tripod/monopod, the same wide-angle camera is used for quick close-up imaging of different parts of the plot right after taking the higher altitude image. Make a visual judgement of the close-up images and note the ground cover characteristics for each image in the log to aid in the classification later.

5. Post processing can be done in two ways:

a) Using generally available software for distortion correction (e.g. Adobe Photoshop or Adobe Lightroom which has ready-made models for most standard cameras, or the Camera calibration application in Matlab to make a custom model) and land cover classification (e.g. CAN-EYE, VegMeasure, SamplePoint, or eCognition). Recalculation of images to overhead projection can be programmed in Matlab using the formulas given in this article (Eqs. 1-2) and using two for-loops to transform each pixel in a lens distortion corrected image to ground coordinates in meters (see Fig. 6).

b) Send images and related information to the lead author who can assist. For this option, we ask image senders to agree on making images and post processed results publicly available via a database hosted by the authors. The aim of this is to over time build a public database that can be used as a source for reference data for remote sensing products.

The post processing software can be requested from the lead author (magnus.galfalk@liu.se). Users should however be aware that the software is not user friendly at its present stage as it is not commercial and that there is limited time for support.

\section{Supplementary material S2 - Four additional examples of classification}
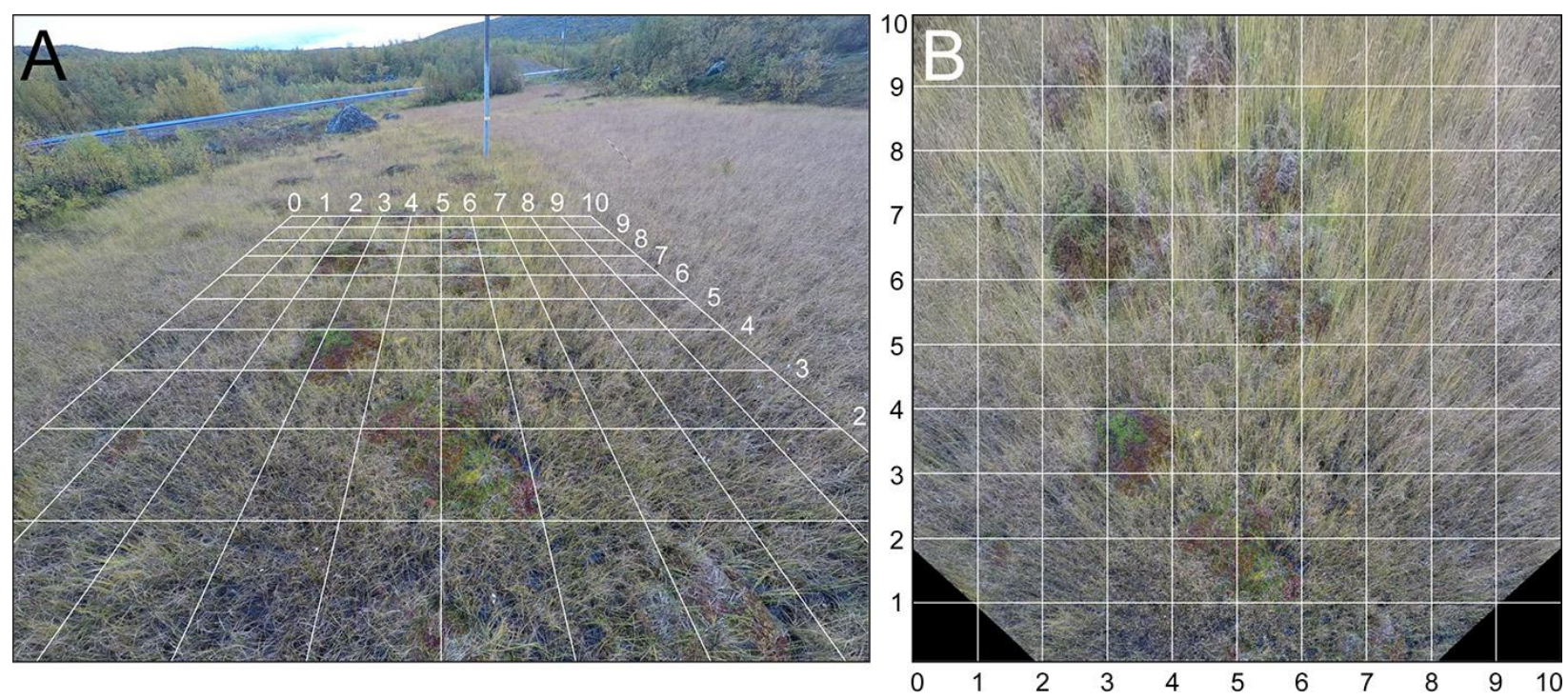
Figure S1: One of our field plots. (A) Image corrected for lens distortion, with a projected 10 x 10 m grid overlaid. (B) Image after recalculation to overhead projection $(10 \times 10 \mathrm{~m})$.
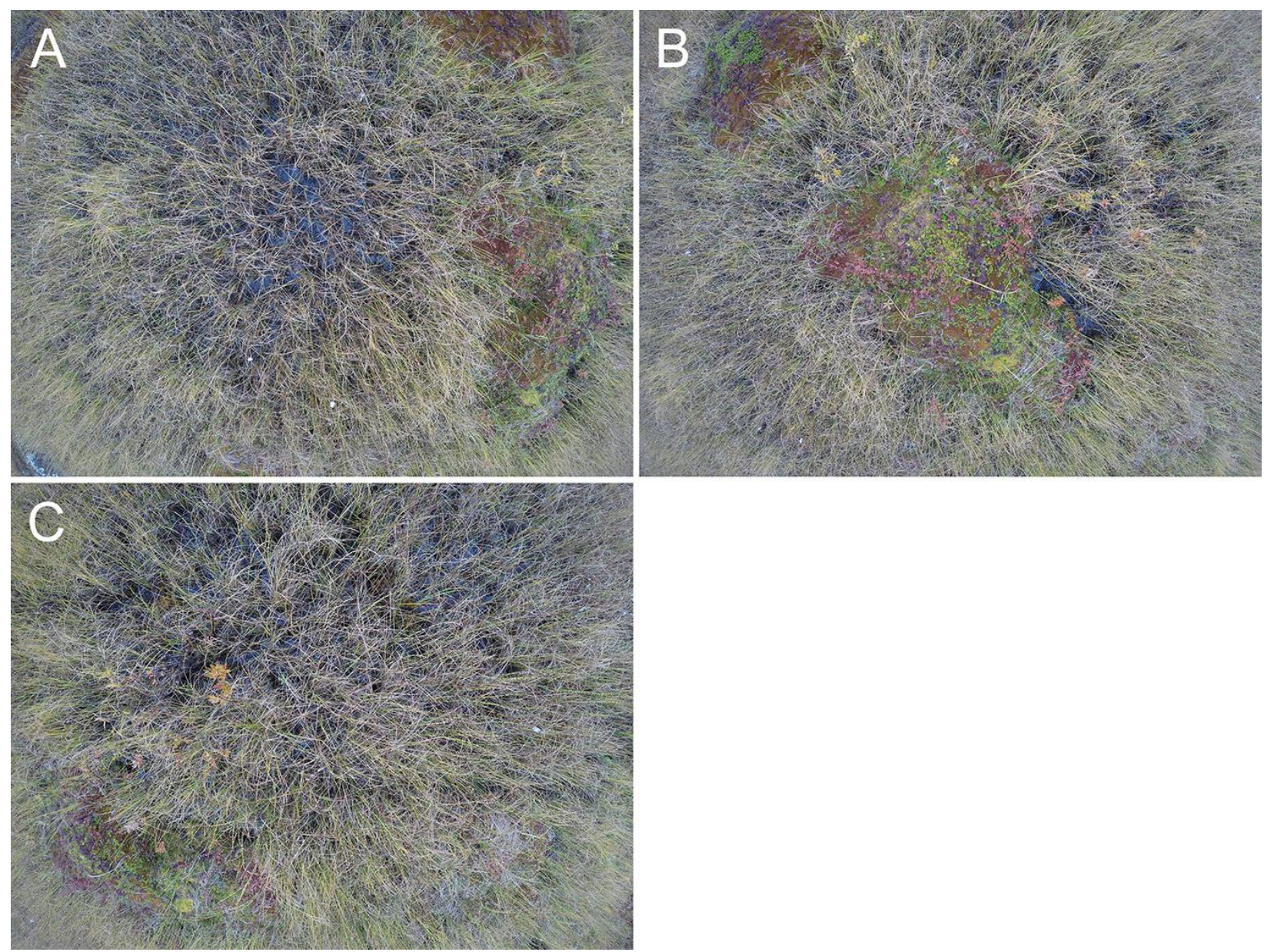

Figure S2: Close-up images in one of our $10 \times 10 \mathrm{~m}$ field plots (Fig. S1). 

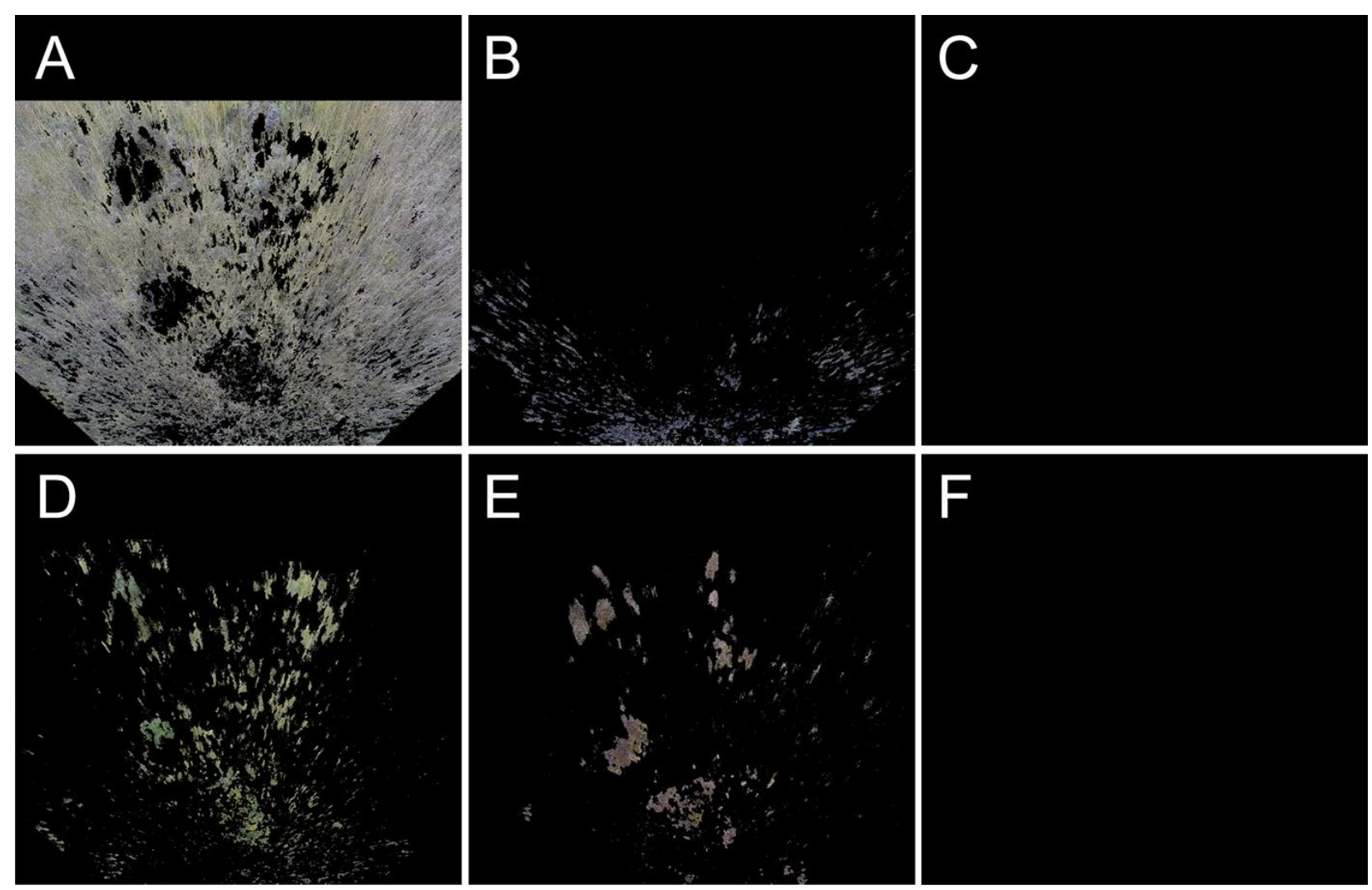

F

Figure S3: Additional example of a field plot image with classification into the six main surface components (the plot shown in Fig. S1). All panels have an area of $10 \times 10$ m. (A) Graminoids. (B) Water. (C) Shrubs. (D) Dry moss. (E) Wet moss. (F) Rock. 

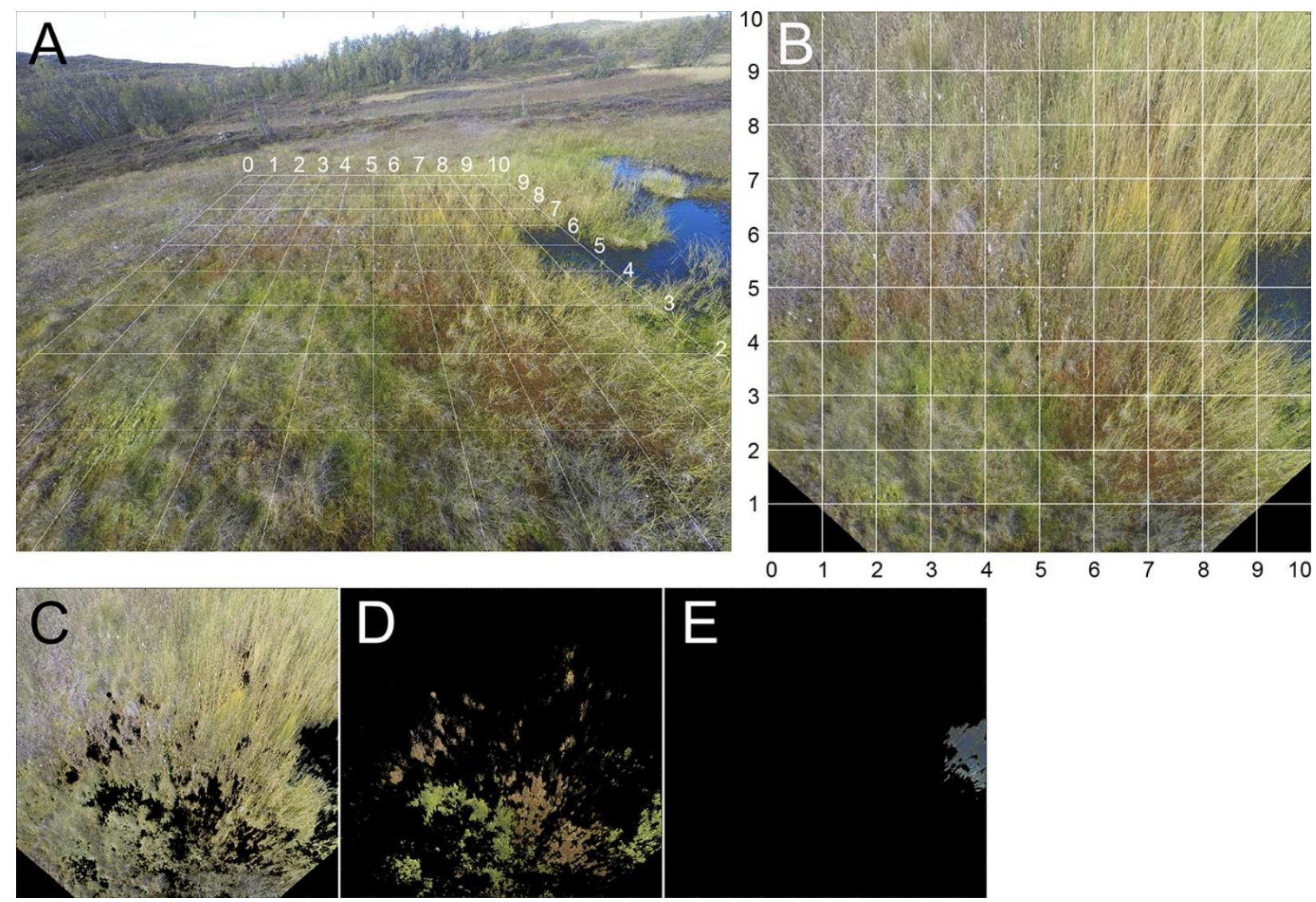

Figure S4: Additional example of plot classification. (A) Image corrected for lens distortion, with a projected $10 \mathrm{x} 10 \mathrm{~m}$ grid overlaid. (B) Image after recalculation to overhead projection $(10 \times 10 \mathrm{~m})$. (C) Graminoids. (D) Wet moss. (E) Water. Images C-E have areas of $10 \times 10 \mathrm{~m}$. This plot is clear example of vegetation of different color belonging to the same class as the wet moss included both green-yellow and red vegetation (field notes about the close-up images showed this to be the case). 

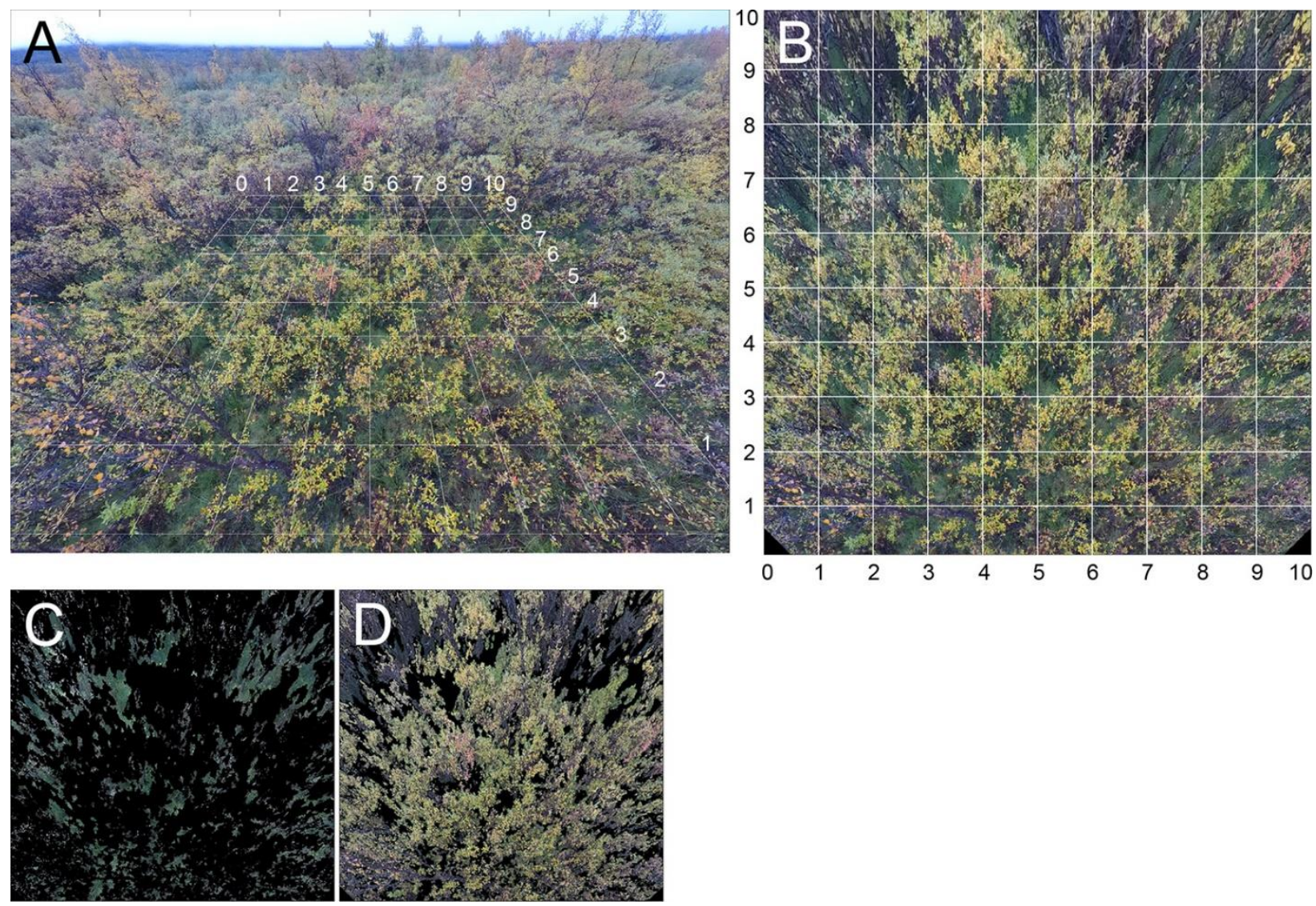

Figure S5: Additional example of plot classification. (A) Image corrected for lens distortion, with a projected $10 \mathrm{x} 10 \mathrm{~m}$ grid overlaid. (B) Image after recalculation to overhead projection $(10 \times 10 \mathrm{~m}) .(C)$ Graminoids. (D) Shrubs. Images $\mathrm{C}$ and $\mathrm{D}$ have areas of $10 \mathrm{x}$ $10 \mathrm{~m}$. 

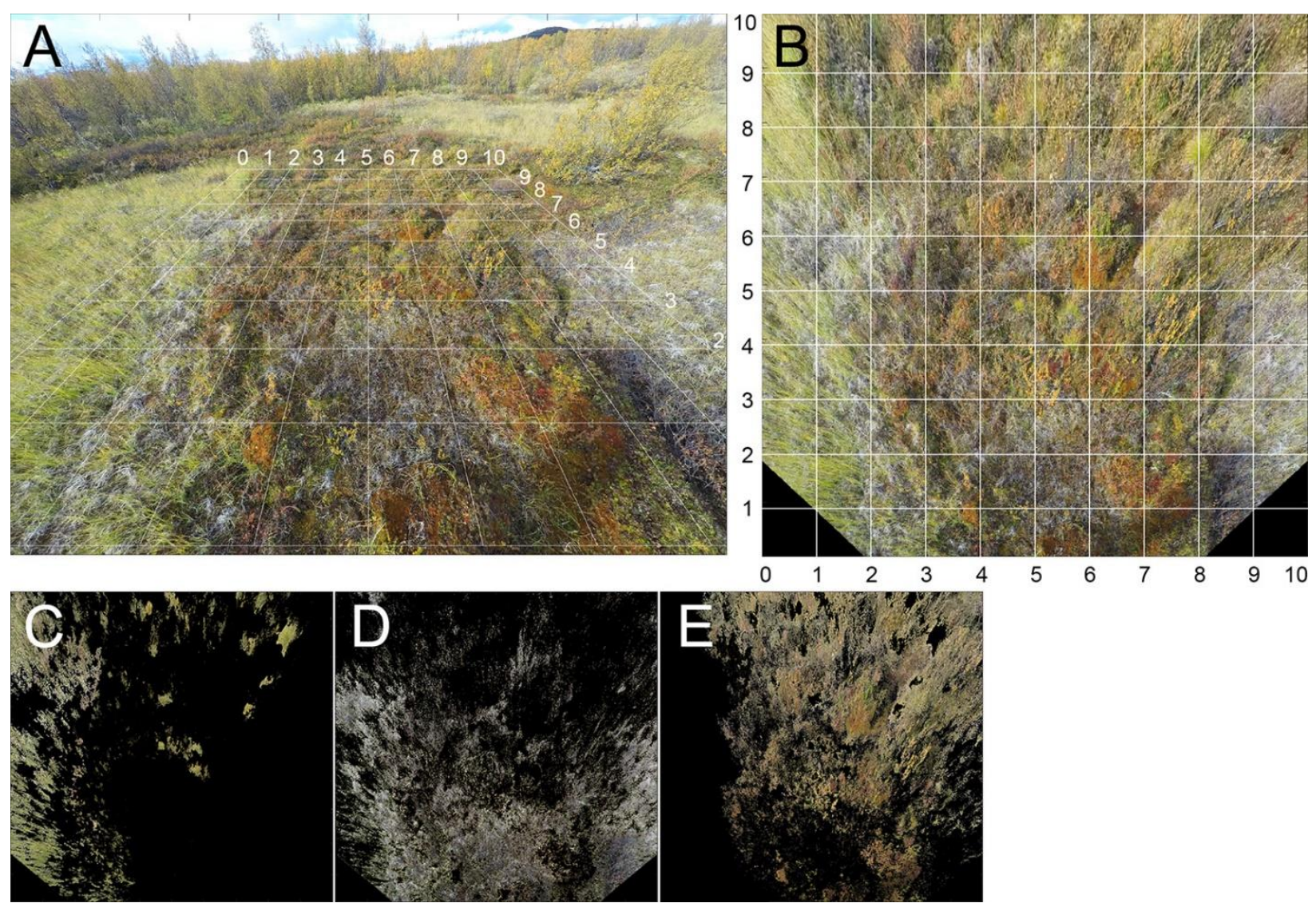

Figure S6: Additional example of plot classification. (A) Image corrected for lens distortion, with a projected $10 \mathrm{x} 10 \mathrm{~m}$ grid overlaid. (B) Image after recalculation to overhead projection $(10 \times 10$ m). (C) Graminoids. (D) Dry moss. (E) Shrubs. Images C-E have areas of $10 \times 10 \mathrm{~m}$. 